\title{
Evaluation of a Prototype of the Mimamori-care System for Persons with Dementia
}

\author{
Taro Sugihara ${ }^{1}$, Kenichi Nakagawa ${ }^{2}$, Tsutomu Fujinami ${ }^{1}$ and Ryozo Takatsuka ${ }^{1}$ \\ ${ }^{1}$ Japan Advanced Institute of Science and Technology, Ishikawa, Japan \\ \{sugihara, ryozo-t, fuji\}@jaist.ac.jp \\ ${ }^{2}$ Freelance programmer \\ macsi@m2.spacelan.ne.jp
}

\begin{abstract}
We aim to clarify the requirements for the mimamori-care system in the group home to support caregivers who take care of persons with dementia (PWD). We investigated the effects of the prototype, which consists of several cameras and monitors, by interviewing eleven caregivers. We found that the prototype system not only helps the caregivers to watch out the people with dementia but also removes some stress caused by taking excessive precaution to residents' behaviors. Caregivers however reported some concerns to the violation of privacy as for the caregivers themselves and the residents alike.
\end{abstract}

Keywords: Mimamori-care system, Caregivers' work stress, Persons with Dementia, and Group home

\section{Introduction}

Japan is entering a super-aged society. There are approximately two million people with dementia (PWD). Group home is a carehouse for PWD, whose number has increased thirty-five times for these eight years, that is, from the year of 2000 to 2008. Despite the urgent need for care support systems and for eligible care workers in group homes, neither qualified persons nor any type of system has caught up the rapid social change.

We endeavor to develop a mimamori-care system to monitor the behaviors of the residents at group homes and to protect them from accidents. "Mimamori" is a Japanese expression, which means to watch someone or monitor something. "Mimamori-care" implies not only watching PWD but also supporting their autonomy to realize an adequate dementia care. A watch system for the elderly had been developed in the past but was not well accepted among PWD and caregivers due to privacy issues. Hence, it is necessary to solve these privacy issues and win their trust in order to induce them to use the digital equipment. Further, it is important to clarify the essence of dementia care. Hospitality and humanity constitute two pillars of caregiving. Therefore, the mimamori-care system should include these two components in the care of PWD as well as to assist caregivers. In order to solve the problems and to ensure reliable hospitality, we elaborate on a new concept; this system adopts the real world-oriented approach and is based on ubiquitous technology. 
Many researches and developments related to ubiquitous technology have been conducted. However, according to the valley of death [1] and the Darwinian Sea [2] metaphors, laboratory results cannot be implemented directly into the real world. There are methodologies such as human-centered design [3] and user-centered design [4] that reflect users' needs, improve usability, and facilitate modification in terms of custom-made design. However, dementia care is a difficult field. It depends heavily on contexts such as the person involved in, the type of care work, the equipment used, and the environment. The conventional approaches to dementia care have not taken them into account. Moreover, it is critical to understand the essence of dementia care with respect to factors such as the autonomy of PWD and their quality of life. Davenport mentioned the problem of infrequently-used systems about knowledge management; Knowledge applications have not been embedded into the flow of the job process with expert knowledge workers [6]. We defined this process as "the real world-oriented approach" and developed our ideas into the Mimamori-care system[5].

In this paper, we clarify the requirements for the mimamori-care system in the group home.

\section{Mimamori-care system}

Unless the technology and its users are mutually coordinated, the technology does not become an advantage for the users. We thus emphasize the viewpoints that the caregivers presented us with. That is, there should be a correspondence between the problem faced by the dementia caregivers and the functions implemented by the system.

PWD usually wander around group homes, which is a source of concern and anxiety for caregivers; the events may sometimes lead to a matter of life and death for PWD. Therefore, it is necessary to always know where PWD are and what they are doing. This system combines the functions of position detection and image capture by means of IC tags and cameras. Thus, caregivers can spot the locations and watch the behaviors of all the PWD through monitors. Figure 1 shows the schematic of the "mimamori-care" system. All the equipments are commercially available. We developed a program that allows the caregivers to communicate with each other. Originally, the intended functionality was to enable two or more caregivers to share

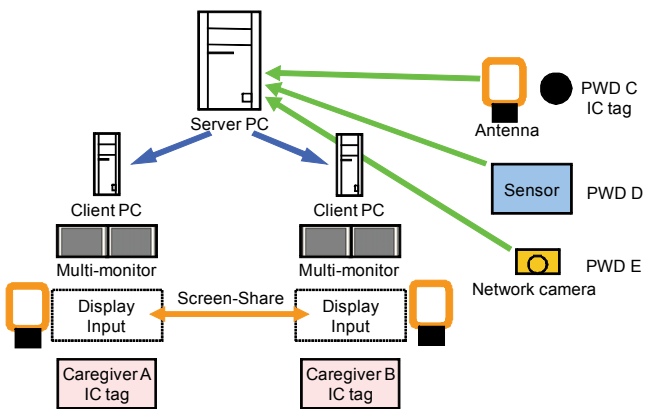

Fig. 1. Structure of the mimamori-care system. 
a screen image, especially during the daytime. Each monitor may display different images dependent on the profile and context detectable based on the data from IC tags and sensors so that only the necessary items of information is provided. The Web context awareness technology [8] we had developed earlier was used for this objective. The server was developed in Visual Basic 6 using the API provided by the IC tag vendor. A Web browser was used to display the information to the client.

It is important that all the caregivers are notified of the collected items of information and that the priority of the work is clearly stated. Before introducing the system to a grouphome, our observation of the caregivers' activities revealed that their work involves a considerable amount of walking. To support their work, we

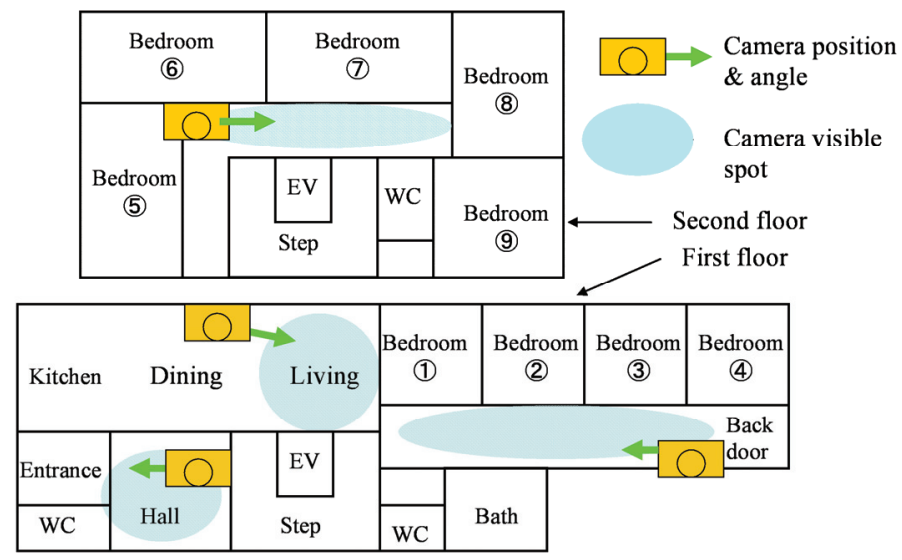

Fig. 2. The Arrangement of Cameras in Group Home A (GH-A).

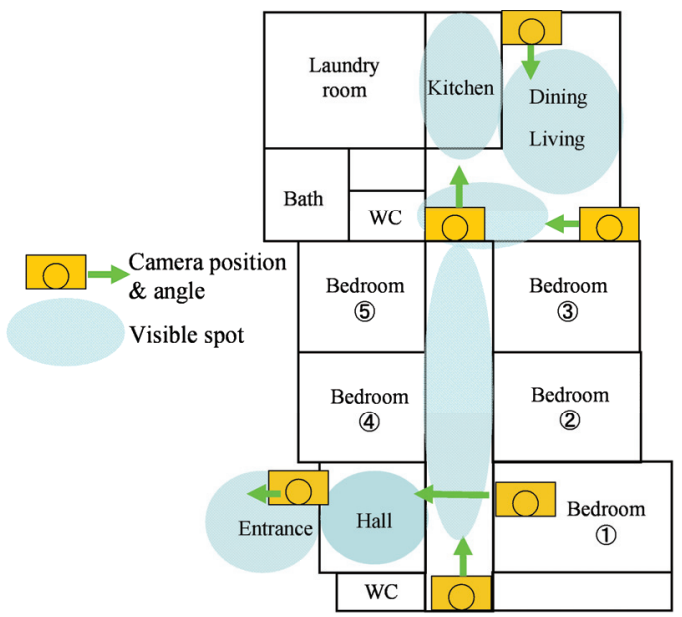

Fig. 3. The Arrangement of Cameras in Group Home B (GH-B). 
introduced the prototype to two group homes. The prototype system is constructed from several cameras and several monitors to investigate issues of caregivers' work styles and stresses. To clarify the cause of changing work styles and stresses, we adopted only cameras and monitors whereas it is important for the concept of the "mimamori-care" system to include IC tags such as RF-ID. We embedded cameras in common spaces except the bathroom and restroom and monitors in the walls, in furniture, as well as in other different objects and places. We thereby created an ambient environment. We considered environments in which water is used, such as bathrooms, kitchens, and restrooms, and adopted waterproof monitors in such environments. We coordinated all these monitors with computers. The arrangements of cameras in the group homes are illustrated in Figure 2 and Figure 3. Group home A is a two-story house and Group home B is a single-story one.

Since the caregivers were inexperienced with computers, we designed touch-screen type monitors with a few buttons to enable even novice users to manipulate them appropriately.

\section{Effects of the prototype on caregivers}

\subsection{Overview of the research}

To investigate the effects of the prototype, we interviewed eleven caregivers in the group homes. We believed it more effective to investigate the efficiency of the system through open-ended responses because the patient, caregiver, and situation change depending on the context [11]. We asked them which aspects they regard to be effective and what they think of the system. In particular, we paid attention to the difference in the uses of the system during daytime and nighttime caregiving. We also investigated how the prototype changed caregivers' mind after the introduction of the system.

Table 1 shows the overview of our interview. The group homes already reach at capacity, and total of caregiver is designated by law. In the daytime both GH-A and GH-B, caregivers work all over the home. They are busy with housekeeping, caregiving the residents who are PWDs, writing the records of the residents' behavior and so on. In the nighttime in both group homes, they mainly stand by around the living room. They may wander around and require an assistance for using the restroom.

The profile of the interviewees is illustrated in Table 2. We classified the caregivers' experience into three levels. Five caregivers are novice about the caregiving in the group home. Their experience is less than three years. Rest of the caregivers is classified as moderate level because they have worked in the group home with 3-7 years. Every worker has the qualification of caregiving and three caregivers in the GH-A have the nursing qualification. 
Table 1. Overview of this interview and group home.

\begin{tabular}{l|cc}
\hline & $\mathrm{GH}-\mathrm{A}$ & $\mathrm{GH}-\mathrm{B}$ \\
\hline Residents & 9 & 6 \\
Total of caregivers & 9 & 5 \\
Intervewees & 6 & 5 \\
Caregivers in the daytime & 2 or 3 & 2 \\
Caregivers in the nighttime & 1 & 1 \\
Residential area & first and & first floor \\
Start of operation & second floor & 2006.Dec. 2005.Jan. \\
Video recording & none 2007.Jun. \\
Timing of interview & \multicolumn{2}{|c}{ on } \\
\hline
\end{tabular}

Table 2. Profile of interviewees.

\begin{tabular}{c|c|c}
\hline Intervewees & Experience level & $\begin{array}{c}\text { Qualification } \\
\text { of nurse }\end{array}$ \\
\hline a1 & moderate & eligible \\
a2 & moderate & eligible \\
a3 & moderate & \\
a4 & low & \\
a5 & moderate & eligible \\
a6 & low & \\
\hline b1 & moderate & \\
b2 & low & \\
b3 & moderate & \\
b4 & low & \\
b5 & low & \\
\hline
\end{tabular}

\subsection{Results and discussions}

Table 3 shows the evaluation points of the prototype and its typical answers. The two caregivers who have worked in both group homes mentioned a lot of good effects to the prototype. In the case of GH-A, they appreciate the effects of eliminating the blind spots, especially nighttime on the second floor. Before operating the system, caregivers had strongly worried when some of the residents is starting wandering on the second floor and how many times residents went to the restroom. When there was a trouble such as wandering, caregivers walked up from the living room to the second floor, which was a big blind spot, and helped or talked to residents. Caregivers could not feel relieved all night long and they could not concentrate on their works to be done. On the other hand, they have many works to do at the nighttime; For example, they have to write records about each residents' behavior (e.g. how many times residents went to the restroom at the daytime, how many times they took a walk, what kind of meal they ate), have to make a breakfast for residents of nine and themselves, have to help residents to change clothes, and have to clean rooms and corridor. They can now focus on the issues at hand.

Moreover, the prototype reduced their work stress by eliminating the blind spots, which brought their work style some change. Before operating the prototype, they felt the stress caused by undue interference. When residents attempted to go out somewhere, caregivers talked to residents too much than necessary. They were afraid 
Table 3. Effects of the prototype.

\begin{tabular}{|c|c|c|c|}
\hline & Evaluation point & Positive effects & Negative effects \\
\hline \multirow{3}{*}{$\mathrm{GH}-\mathrm{A}$} & blind spots & $\begin{array}{l}\text { - eliminated, especially at nighttime on } \\
\text { the second floor. }\end{array}$ & none \\
\hline & change in work style & $\begin{array}{l}\text { - the caregivers easily monitor the } \\
\text { activities of the PWD and take } \\
\text { - the caregivers keep the focus on the } \\
\text { issues at hand, especially at nighttime } \\
\text { - going up and down stair has been } \\
\text { reducing }\end{array}$ & none \\
\hline & work stress & $\begin{array}{l}\text { - the caregivers have attained the } \\
\text { peace of mind because of eliminating } \\
\text { - the caregivers have obtained the } \\
\text { relief because of reducing undue } \\
\text { interference to the residents }\end{array}$ & none \\
\hline \multirow{4}{*}{$\mathrm{GH}-\mathrm{B}$} & blind spots & $\begin{array}{l}\text { - eliminated, especially at daytime on } \\
\text { the hall and the entrance. }\end{array}$ & none \\
\hline & change in work style & $\begin{array}{l}\text { - the caregivers easily monitor the } \\
\text { activities of the PWD and take } \\
\text { - the caregivers keep the focus on the } \\
\text { issues at hand }\end{array}$ & none \\
\hline & work stress & $\begin{array}{l}\text { - the caregivers have attained the } \\
\text { peace of mind because of eliminating } \\
\text { - the caregivers have obtained the } \\
\text { relief because of reducing undue } \\
\text { interference to the residents }\end{array}$ & $\begin{array}{l}\text { - the video recording leads to high } \\
\text { levels of stress to the caregivers } \\
\text { - the caregivers cannot rest in the } \\
\text { break time because of the video } \\
\text { recording }\end{array}$ \\
\hline & video recording & $\begin{array}{l}\text { - the caregivers can check where the } \\
\text { resident are hit in the falling accident }\end{array}$ & $\begin{array}{l}\text { - the caregivers are heavily stressed } \\
\text { because of violation of the privacy } \\
\text { rights with themselves, co-workers and } \\
\text { residents. }\end{array}$ \\
\hline
\end{tabular}

of losing the sight of residents because they are not would like to wound by accidents. "We can do mimamori-work more effectively than before," one of the caregivers said after introducing the prototype. Recently, they felt that residents live more independent lives owing to the system. As a consequence, we have accomplished that our prototype provides caregivers with leeway to take adequate action to residents. It is important for caregivers to have the leeway. It reduces the number of errors in judgment, enhance the conversation time with residents, and improve the quality of life for residents. If caregivers are not provided with a leeway, they will lose not only motivation but also creativity. In the case of GH-A, caregivers do not mention about bad effects.

Although almost good effects for caregivers in the GH-B are as same as GH-A, the prototype works more effectively in the daytime. One of the residents has a habit of taking a walk, and GH-B do not lock the door to the entrance. Before operating the system, caregivers sometimes passed over resident's outgo. It is difficult to notice the behavior because caregivers may be at a location from which they cannot observe the residents. After installing the system, the caregivers can monitor the activities of the PWD and take adequate reaction. They said "the system is half worth of a caregiver" and "my sight is enhanced." However, they also reported of negative effects of video recording, which violates the privacy rights of themselves and residents. Despite the fact that they recognize the advantage of video recording (e.g. the caregivers can check where the resident is hit in the falling accident), they are heavily stressed (e.g. the caregivers cannot rest in the break time). Earlier, some caregivers experienced stress while caregiving residents. However, this system decreases the guilt for 
residents' privacy. The problem is very important because it becomes inhibition effect to the caregivers' creativity. If caregivers strongly feel that they are under constant surveillance by someone, they would feel threaten. There is a trade-off between this problem and the advantage of the video recording. Therefore, it is necessary to pay attention to caregivers' feelings continuously.

\section{Related works}

In Japan, one of the most well-known researches using radio frequency identification (RFID) is a tracking system for elementary school pupils [9]. These systems typically use active RFID by which pupils can be automatically identified at the school gate. On the other hand, researchers also used Global Positioning System (GPS) to verify the location of wandering the elderly [10]. The problem, however, occurred when a resident removed the device due to its stumbling block. In the mimamori-care system, we used a $13.56 \mathrm{MHz}$ passive RFID tag, which can be used permanently and does not require batteries. The RFID we used effectively communicates within the range of 70 $\mathrm{cm}$. As our target is a typical house, this range does not pose a problem. By installing antennas in passages and on doors, we can effectively use this RFID. Using the above-mentioned RFID, we experimented whether movements could be detected in each room.

For the nursing action in hospitals, the e-nightingale project, which focused on recording with wearable sensors, was proposed [11]. Our target is not to record the nursing action in hospitals but to support PWDs' self-reliant life in group home.

\section{Conclusions}

This paper presents the mimamori-care system and its effects on caregivers. Our results show that the system was effectively used in both daytime as well as nighttime caregiving at two group homes. Despite the system makes peace of mind, which is one of the most important factors for the mimamori-care works, the system caused some stress to caregivers, who are concerned with violation of the privacy rights. One of the purposes of caregiving is the independence of PWD; this system encourages PWD to be more independent. Although this system does not intend to be a substitute for caregivers, it provides them with considerable support. The reason for the positive vibes in group homes is the comfortable, homelike environment. In these surroundings, PWD are not only caregiven but are also able to engage in other activities of daily life. Caregivers are enabled to peacefully make improvements in the quality of care. 
Acknowledgments: Our research is partly supported by the fund from Ministry of Education, Culture, Sports, Science and Technology, Japan, under the name of Cluster for Promotion of Science and Technology in Regional Areas.

\section{References}

[1] C. Wessener, Public/Private Partnerships for Innovation, US National Academy of Sciences, OECD Workshop, 2001.

[2] L.M. Branscomb and P.E. Auerswald, Between Invention and Innovation An Analysis of the Funding for Early Stage Technology Development, Report to the Advanced Technology Program, NIST, US Department of Commerce, GCR-02841, 2002.

[3] R. Takatsuka and T. Fujinami, Aware Group Home: Person-Centered Care as Creative Problem Solving, 9th International Conference on Knowledge-Based \& Intelligent Information \& Engineering Systems (KES2005), Lecture Notes in Computer Science, Springer-Verlag GmbH, pp. 451-457, 2005.

[4] ISO13407, Human-centred design processes for interactive systems, 1999.

[5] Nakagawa, K., Sugihara, T., Koshiba, H., Takatsuka, R., Kato, N. and Kunifuji, S., Development of a Mimamori-Care System for Persons with Dementia Based on the Real World-Oriented Approach, Proc. of 11th International Conference on Knowledge-Based Intelligent Information and Engineering Systems (KES2007), Part II, LNAI 4693, Vol. II, pp. 1261-1268, Vietri sul Mare, Italy, 2007.

[6] Davenport, T.H., Thinking for a Living: How to Get Better Performances and Results from Knowledge Workers, Harvard Business School Press, 2005.

[7] H. Kanai, H. Nakada, G. Turuma, and S. Kunifuji, An Aware-Environment Enhanced Group Home, International Workshop on Smart Home (IWSH2006) in conjunction with International Conference on Hybrid Information Technology, 2006.

[8] K. Nakagawa, N. Kato, Y. Ueda, S. Kunifuji, A proposal and an implementation of a context-awareness system for web-based collaboration, IPSJ 47(7), 20812090, 2006.

[9] I. Yamada, S. Shiotsu, A. Itasaki, S. Inano, K. Yasaki, and M. Takenaka, Secure Active RFID Tag System, Proceeding of UbiComp 2005 Workshop on UbiComp Privacy "PRIVACY IN CONTEXT," 2005.

[10] K. Shimizu, K. Kawamura, and K. Yamamoto, Location System for Dementia Wandering, Proceedings of the 22nd Annual International Conference of the IEEE Engineering in Medicine and Biology Society, 4928-92332.pdf(CD-ROM), 2000.

[11] N. Kuwahara, H. Noma, K. Kogure, N. Hagita, N. Tetsutani, and H. Iseki, Wearable Auto-Event-Recording of Medical Nursing, Proceedings of INTERACT2003, 2003. 